\title{
RTA Analysis \& Existing Modelling for Emergency Medical Service
}

\author{
Muhammad ASIM AZIM, Dang JIANWU, Wang YANGPING, Tarique AZIZ, Zhai FENGWEN
}

\begin{abstract}
Prevention of accidents is extremely difficult in absence of present situation analysis, as the aim to identify the incident locations and safety deficiency area is the key to work out the effective solution. To access the feasibility of using Geographic Information System (GIS) for mapping of incident locations with an existing data source is vital to estimate variation of RTAs (Road Traffic Accidents) pattern by interpolating. Generally, accident particulars like location, date, time, sex and suspect are included in GIS database. Here, Arc GIS (10.2.1) software is applied to identify incident locations in Karachi district. To reduce the accidents in particular area/study area and in order to sustain coverage for emergency response, there may be such more factors including the number of ambulances deployed, their position/location, and dispatching strategies that affect the EMS system, authors strictly recommended covering based probabilistic model for (Rescue-15) solving the problem of ambulance locations. GIS facilitates the respective authority to do assessment and to analyze the entire position of the accident with the help of GPS or additional sources of information while consequences are utilized as part of the preparation progression is based on the acuity of the patient in time.
\end{abstract}

Keywords: EMS; GIS; Karachi (Pakistan); Spatial Analysis

\section{BACKGROUND}

\subsection{Population Trend \& Cost: 1998-2011}

According to preliminary results of Pakistan census, in 2011, population of Pakistan estimated 197.5 million from 1998 to 2011 and this was predicted by the United Nation documents. The reason for the expansion was migration from rural areas to Karachi. But these efforts were not sufficient to estimate accurate population with zero projection error. At Present Pakistan is considered to be the most populated country and has passed Brazil to become the world's $5^{\text {th }}$ most populated nation, after China, India, US and Indonesia. 11 years growth rate is projected at $34.2 \%$, nearly double to Mexico with an estimated 18.2 percent. According to the most populated nation growth rates show that Pakistan population growth rate is more than India (estimated 15.9\%) and Bangladesh (estimated $14.1 \%)$. As following this growth rates, Pakistan can become the world's $4^{\text {th }}$ populated country by 2030 . The population data from the United Nation is calculated according to preliminary results of Pakistan census respectively: Population growth rate up to the years from 1998 to 2011 shows that Karachi is the $3^{\text {rd }}$ largest city across the world and $7^{\text {th }}$ largest populated city in the Muslim world, with an estimated population of 23.5 million, in 2011. Urbanization is extensive with large numbers of road networks connecting hospitals, industries and educational institutions. The last little while projected survey estimated between 2001 to 2006 economic development and Car loans rate irrespectively increased by over $300 \%$ [1-3]. With an estimated population of Karachi is more than ten million of people because of that, Karachi is considered to be a megacity like Mumbai (India) and Dhaka (Bangladesh). Karachi grew even faster, between 1998 to 2011; Karachi population grew up 9.8 million to 21.2 million, adding more than 11 million people (115 percent) as shown in Tab. 1. These 13 years growth rate has been adjusted to ten years, with an estimated 8.8 million. Over the last decade, only Tokyo, over the metropolitan had grown more than 6 million in 10 years, 6.2 million during 1960 to 1970 . During years 2000 to 2010, Jakarta growth rate was adjusted 7.4 million and Shanghai growth rate was adjusted 7.0 million, (as show in
Fig. 1). This time period roundabout $10 \%$ density is (within house units) increased.

Table 1 Population record source

\begin{tabular}{|c|c|c|c|c|}
\hline Year & Population & Increased & In- $\%$ & AAGR / \% \\
\hline 1951 & $1,068,500$ & 632,600 & 145.11 & 9.3 \\
\hline 1961 & $1,912,600$ & 844,100 & 78.90 & 6.0 \\
\hline 1972 & $3,515,400$ & $1,602,800$ & 83.80 & 5.6 \\
\hline 1981 & $5,208,000$ & $1,692,600$ & 48.12 & 4.4 \\
\hline 1998 & $9,802,184$ & $4,594,184$ & 88.20 & 3.6 \\
\hline 2011 & $22,123,000$ & $1,232,0816$ & 115.00 & 8.8 \\
\hline
\end{tabular}

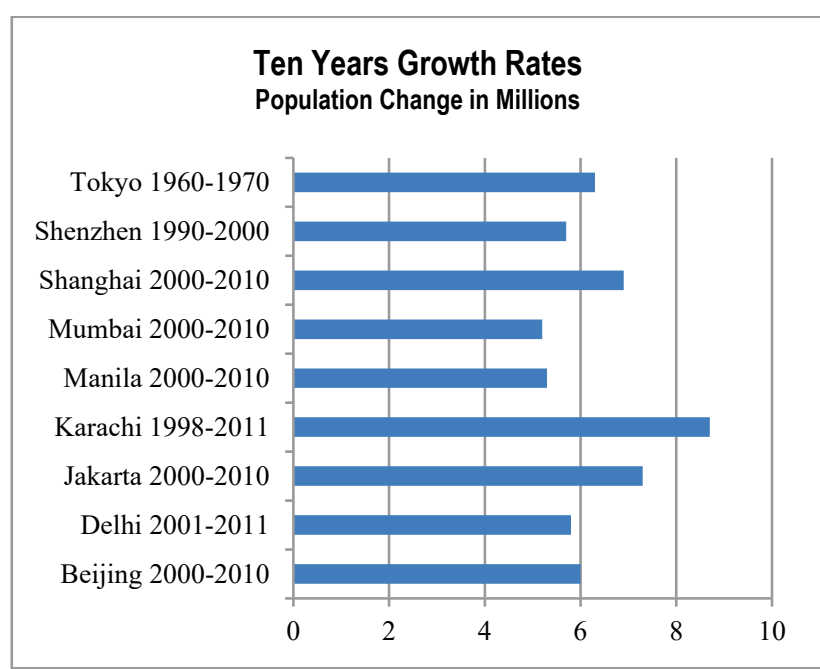

Figure 1 Largest region historical growth rate

Without any doubt, this recent population growth rates is alarming and Karachi can be become the most populated city in the world till 2030. The unpredictable growth rate in urbanization and motorization is continuously contributes to enhance the risk that is economically, socially and environmentally unsustainable. Whereas Karachi is considered as urban (largest) city and economic Centre of Pakistan, growth ratio of motorization in Karachi with inadequate infrastructure to handle the present situation and lack of concern from (provincial) government agencies has led to the significant level of RTAs, traffic jams and congested population. Uncertain safety situation and rapid growth in volume of vehicles is a major cause of road crashes and causalities. Cost is associated with trauma 
Centers admissions that are putting massive burden on low income countries or less resources countries.

\section{INTRODUCTION}

During the year 2009, it's revealed that there are two types of groups are very active and have an influence in most of incidents; riders and pillions of two wheels vehicles and pedestrians. But the most registered fatale victims were pedestrians. Based on an estimated only $7 \%$ motorcyclists were found to be wearing helmets at accident time and common accident cause was rear-ending collision. Most accident victims were found with external wounds, such as lacerations, abrasions, etc. Overall reported outcomes confirmed that injury patterns are normally similar those reported in major cities from low or middle income countries. However, there are a few differences in overall incidence and mortality rate. It is estimated that there is a large number of male victims or a large percentage of victim's admission dramatically increase in different trauma centers (Karachi) [4].

In order to control unexpected loss of property or human life Emergency Medical Service (EMS) is a typical organization which usually assures community/public safety addressed by different emergency occurrences. Many agencies are engaged in safety awareness and prevention programs, to avoid, detect and report emergencies efficiently. Normally these services respond to 12 to 14 emergency calls per day. The huge numbers of calls are received or recorded by public via mobile/telephone calls. Whereas each emergency have marking been various positions by main station. It is estimated by Faster (2004) that large numbers of vehicles are impassioned by highway environment which demands more resources to identify incident location and to progress efficient system. Thus, to deployment of ambulances is a difficult task in intense environment and short distances make it possible to save a lot of lives.

\section{ECONOMIC COSTING BY RTAs}

There are elements need to be overcome that have an influence to increase numbers of road casualties right of path across the world (Hakim, 1991). This is an alarming state, only in 2012 , total 33,114 cases were admitted in different trauma and health care centers (Karachi) in which 1,115 cases were related to fatalities, 6,772 cases related to serious injuries and 25,187 cases were related to minor injuries. It is estimated that according to categorization of the cost impact of accidents which are resulting accumulative effect of these measures, is approximately sixty percent that means huge space for improvements required in this study area.

Gul estimated that restoration cost is contributing $61 \%$ of the total cost per year. It is followed by cost arising from the loss of (total) resources which comes to $30 \%$, whereas a small share of $9 \%$ is taken by the human incapacitation due to psychological reasons. Specially, in Pakistan there is a constant increase with respect to time for cost arising from restoration and loss of resources. This has been noticed in different times that human efficiency has also been decreased between 5 to 15 percent after minor accidents. From economics point of view, accident is a phenomenon which has only cost flows out and no revenue is in flow.

\section{CASUALTY PATTERN BY EXISTING DATA SOURCE}

There are several sources regarding data description; such as by newspaper, police, trauma/health care centers, insurance companies, questionnaire based reports and selfconducted survey reports. All resources included with their advantages and weakness. Even Police data not done properly, there have many other considerable reasons including police workload problems. Including, police staff is not specialists in crash accountability, so important information regarding accidents not be documented properly. It also has been seen, most give and take matters has been made between conflict parties. Most of causalities are reported by different trauma centers (Karachi) this practice also useful to manage the records. With lack of resources, road traffic injury research and prevention centre (RTIPC) Being foremost in data collection and present situation (see Fig. 2).

With the rapid growth in amount of vehicles, the ratio in the vehicle accidents is increasing dramatically. It is now necessary to recognize what will be significance connected with actual issues and how these problems might be proper explain. This optimization pushes as much work as possible to the target. Incidents data is the source for analysis and describing road traffic safety problems. An injudicious action is the worst cause with 44\%, in 2012 . Even it is possible to use micro analysis with possible counter measures.
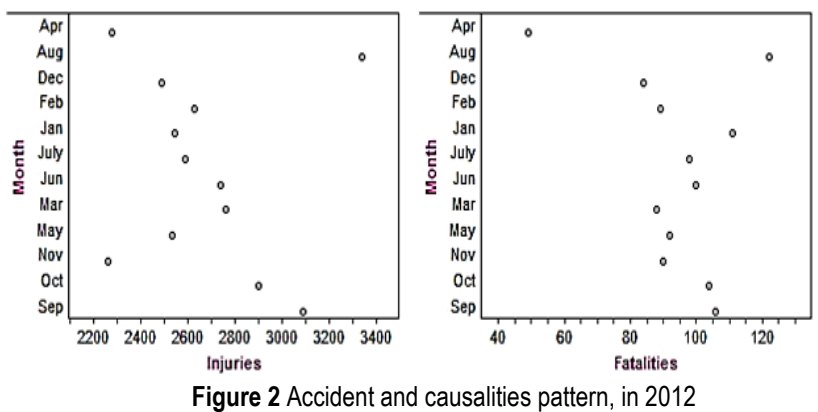

\section{GIS CONTRIBUTION IN FEATURE STUDY}

Geographic Information System (GIS) delivers excellent analytical results along with the actual facts, as well estimate the pattern and trends to forecast effective solutions. Identification of incidents locations through implementation of GIS application in modern age becomes well-known mechanism to constructive results [5] or sharing valuable Geo-information regarding safety prevention. From last few decade, in Karachi (Pakistan) have raised the issue of quality data and its limitations. Frequently attributes such as population, demographic characteristics and environment are difficult to find out without any sequence.

GIS Application has capability in depth analysis and able to produce maps get along with special geographic information. Now, there are various research centers and specialists they are working on RTA analysis, but the problem is that they are facing many problems to complete sufficient RTA database. The Govt. departments are 
collecting only number of causalities but do not have details regarding victim/suspect profile and pinpoint location. The traumas centers have record of admitted patients only. There is no pertinent mechanism do most of times instant deaths often not reported at any hospital or concern authority.

It is very important to know that RTA database is mostly used in micro analysis because the data is reliable and has detailed information regarding each incident. With use of emerging technologies, such as GPS, printers and magnetic stripe and barcode readers has been suggested for database improvements. Thus, GIS in transportation is considered as power tool to arrangement identification of incident's location. Because statistical methodologies can only provide the low and/or high points (information) but can't forecast the cumulative impact of scattered incidents.

\subsection{AADT Data for Karachi}

AADT is the observation of Annual Average Daily Traffic (AADT) volume is significant regarding to evaluate (traffic) flow attributes and to check congestion condition. Vehicle mile or $/ \mathrm{km}$ travelled indicates the total number of vehicle owner, person trips and distance traveled on the roads. For instant, it is imperative to note that if one vehicle can make two trips around about 20 miles or $32 \mathrm{~km}$ per day. Karachi is considered to be most populated city consist of comprehensive roads networks, and limited traffic counts of twelve hours to sixteen hours for selected roads. It is estimated that the average speed and hourly traffic volume within 24 hours can effect on the results significantly, as found in the preliminary studies. In 2001 a test of one-section on Highway six, East near University of Mississippi Campus noted that within 24 hours distribution of traffic volume, and measured 26,645 (AADT) vehicles per day and The 1-m used for traffic counts was 2000 on March, 27. March 7, 2007 at 11:36 AM [6-8], this methodology was applied using $0.6 \mathrm{~m}$ (Karachi-1 imagery) and Google Earth imagery in entire Karachi (city) to estimate average AADT value, according to road classification (see Fig. 3). The roads classification and/or area (type) factors are significant and the statistical results are very important to The roads classification or area (type) factors are significant as well statistical results are important too, that create opportunity of geographical representation for entire metropolitan city (Headrick, 2010), see Fig. 4.

Geographically AADT values significantly high inside the city, which 2.4 times the AADT value in the outskirts. The total average-AADT value approximately 9.3 million is practically accurate considering:

- $\quad$ Average AADT 4 to 6 per day possibly made by 1.8 registered vehicles in Karachi.

- Public transports serve the public by making up to 15 trips per day, and

- Many other trucks are serving the port areas or linked with port areas for carrying their cargo across the country.

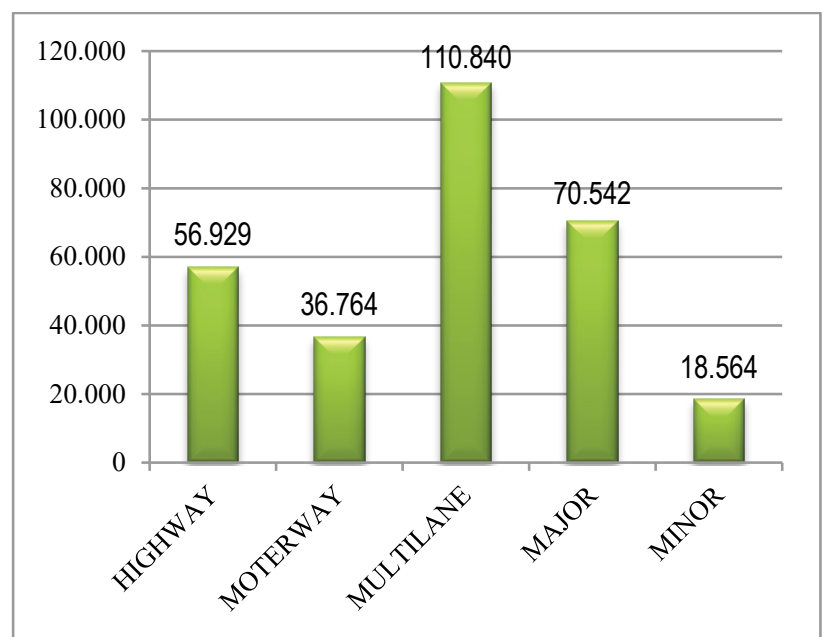

Figure 3 Average AADT-according to road classification

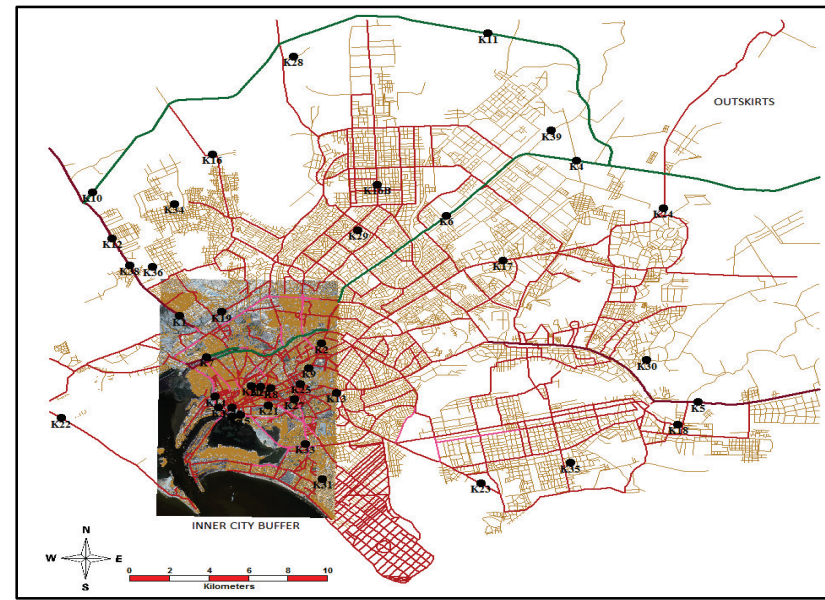

Figure 4 Geographically representation of Average-AADT, according to road classification

\section{ROLL of GIS RTA ANALYSIS}

The foremost common use of GIS is a mapping that is quite important in RTAs research. Meanwhile, identification of accident locations with respect to road causalities on different maps is the main objective of GIS contribution in RTAs analysis, and identification factors is the base for further analysis. Incident position interpolating by special distribution of high or low RTAs is documented. Prevention of accidents is extremely difficult in absence of real time situation analysis as the aim to identify, the incident locations and safety deficiency area by means to work out the effective solution. So these following steps were taken to reach outcomes of the study:

\subsection{Map Scanning}

To assessment of Karachi district topographical map at sale of 1:250,000 were scanned as the raster input.

\subsection{Geo-Referencing}

Scanning maps do not hold information as to where area required representing on the map, fits one surface of the earth. Herein, to set up relationship between an image coordinates system and a map $(x, y)$ coordinate system to align the raster data. 


\subsection{Digitizing}

Digitizing is the process, which encoding of the features in digital from as $\mathrm{x}, \mathrm{y}$ coordinates. This process carried out to create spatial data from existing hard copy of map/maps and documents. Here, geo-referenced raster image of Karachi district is digitized by using Arc GIS 10.2.1, is called on-screen digitization and incident locations Karachi district map based on road network are digitized as line features (see Fig. 7) in which incident locations are represented/digitized as point features. It is also to be noticed that spatial data were organized in a personal geo database and feature class. To find exact incident locations of particular incident digitized $/$ marked by knowing its distance or $x, y$ coordinate from particular station.

\subsection{Assigning Attributes}

In this case, various feature layers are created, "with regard to" the given content in Tab. 2, and these feature layers also used for RTA analysis in Karachi. All relevant data (i.e. line, polygon and point feature) contained separate attributes table. Here, each feature is labeled with its own corresponding name, similar the incident location attributes includes the following data. These layers mentioned in the following table are utilized for identification scenarios associated to RTAs distribution. This typical desktop GIS have composed layer structure for our feature study, in which each feature represented by ArcGIS version 10.2.1.

Table 2 GIS feature layers used in RTAs analysis-Karachi
\begin{tabular}{|c|c|c|}
\hline $\begin{array}{c}\text { Layer } \\
\text { Name }\end{array}$ & $\begin{array}{c}\text { Type } \\
\text { Topology }\end{array}$ & Description \\
\hline RTAs & Point & Causalities Locations \\
\hline $\begin{array}{c}\text { EMS } \\
\text { Shelters }\end{array}$ & Point & $\begin{array}{c}\text { (included hospitals, trauma centers \& } \\
\text { Rescue Stations ) }\end{array}$ \\
\hline GPS & Point & Incident Locations \\
\hline Analysis & Point & $\begin{array}{c}\text { RTAs points summarized on the basis of } \\
\text { their location }\end{array}$ \\
\hline Roads & Line & $\begin{array}{c}\text { Main, Secondary, Arterials and Links } \\
\text { Roads }\end{array}$ \\
\hline Even Points & Point & $\begin{array}{c}\text { Points grid generated at 500 m distance, } \\
\text { covering entire Karachi (city), Pakistan }\end{array}$ \\
\hline Area & Polygon & Karachi district City, Pakistan \\
\hline
\end{tabular}

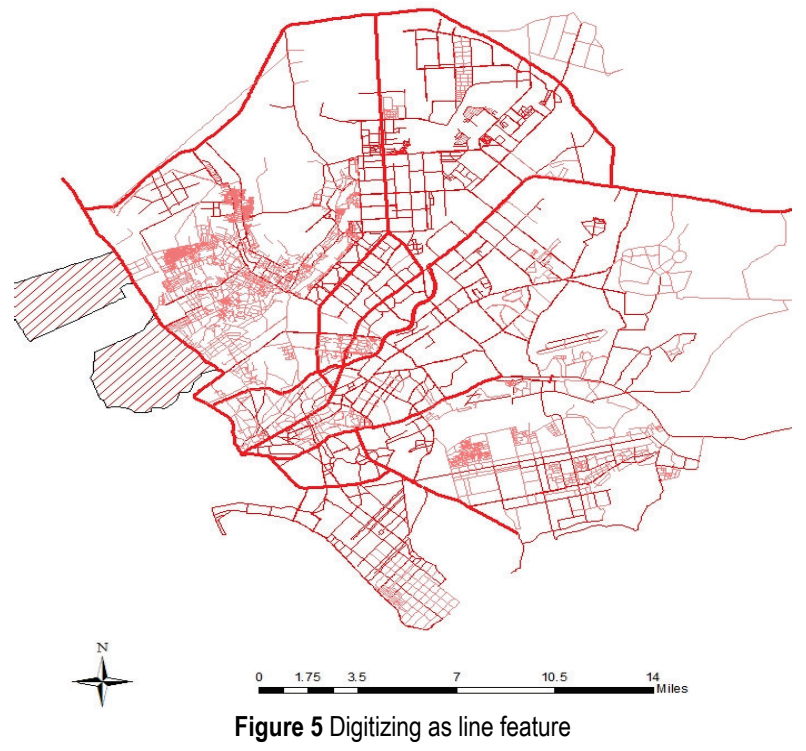

Furthermore, the accident database has several attribute values which are used to produce thematic maps, included: RTA ID, time, date, location (address), IM number, Number of IM (male injury) and age, Number of FI (Female injury) and age, description of victim, accident and suspect. Sometimes during investigation is required surprising results; specially regarding to shows limited variation like day of the week, in this case RTA tabular data is very significant to shows major proportion of the victims. The defined (tabular) attributes information makes possible to develop spatial distribution maps concerning victims, suspect and locations.

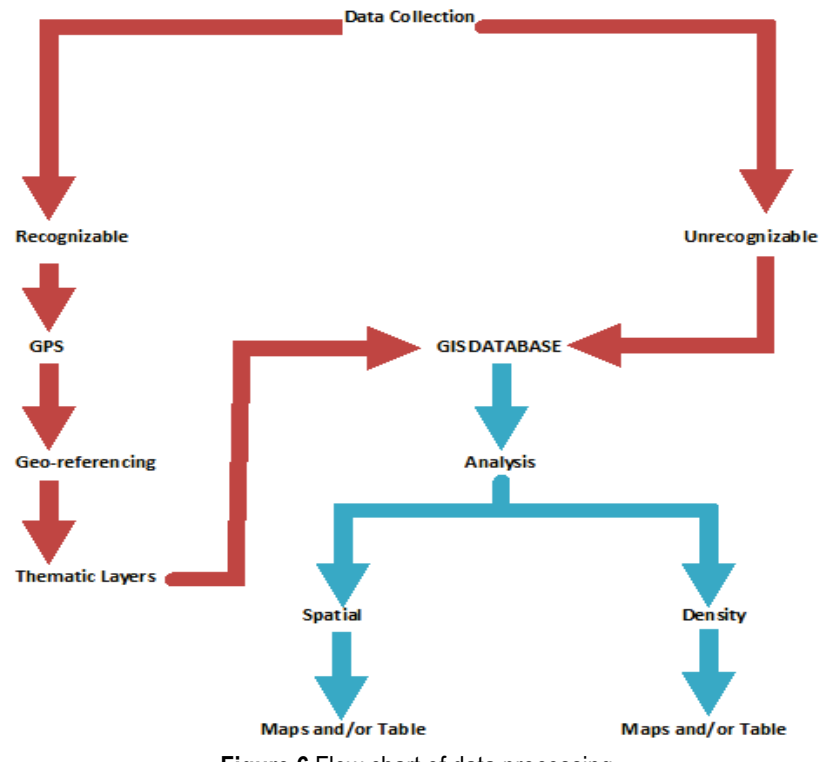

Figure 6 Flow chart of data processing

\section{RTA ANALYSIS}

The foremost common use of GIS is a mapping that is quite important in RTAs research. The flow chart of the data processing is shown in Fig. 6. Additional, the grid point generated at $500 \mathrm{~m}$ distance, that covering entire city (Karachi), whereas identified incidents points the data of latitude, longitude plotted on the vector map. Some points were not recognizable, so left being plotted. Foremost, these following steps were taken to reach outcomes of the study:

\subsection{Variation Respectively Years: 2008, 2009-12}

Visual presentation of any information makes complex phenomenon while the complete database demands thorough study. In Karachi, Techniques has already been implemented on, to create map of incident locations. The database is not following standardized structure or well developed, therefore it is very important to create database for meaningful results. The scattered points can't help to confirm actual pattern or trend. A generalization is required and it is accomplished by different techniques at each steps. A generic location with incident points, is generalized by dividing (total) incidents road length and the placement at equal distance. These points are divided at equal distance because each point has influence over the respective road segment. Each of accident location is marked and actual with respect by following data source included: RTI-2008, 
different newspapers, hospital/trauma center data, police data, ambulance data [9-13], and used hand held Global Positioning System (GPS) for glance RTA pattern and variation for the respectively year(s), as per availability (see Fig. 7). Complete data has detailed information about incidents and almost covering total number of causalities (deaths and/or injuries). A generalized map as shown in Fig. 8, the RTA data is based on location give the impression a little different from initial map. It delivers clear visibility and much better understanding of the phenomenon, as shown in Fig. 9 and 10. No doubt, a lot of work is required to maintain (proper) data base regarding to understand actual facts and figures. But GIS is capable to customized maps to fulfill requirements. Once attributes stored in feature layers then database can be use as additional for manipulation or statistics. Between 2009 to 2012 estimate of variation RTA's pattern change, is represented by interpolating. Geographically AADT values significantly high inside the city, which 2.4 times the AADT value in the outskirts, as shown in Fig.11. The spatial analysis has not been confined to any particular class or type of RTAs analysis but it to be considered in all irrespective types of involved vehicles in each classified area by developing density map within city. Road density $/ \mathrm{Km}$, each of particular area is determined by intensity (of search area) to applied in the output raster being created. Meanwhile, the results shows to identifying (Sadder Town) the highest road density (per km) concentration area by geographically representations are useful for looking patterns rather than to determine at each classify area location per $\mathrm{km}$ to promote save practice at particular search area or location, as shown in Fig. 12.

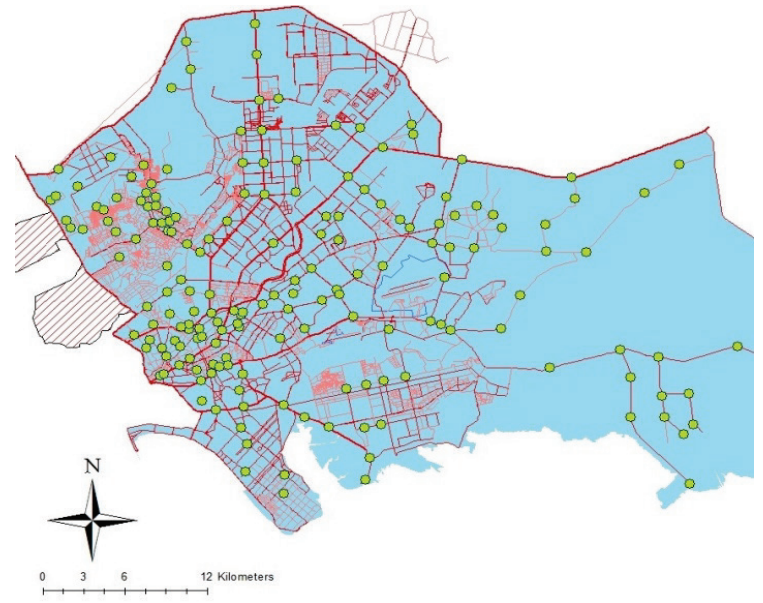

Figure 7 Incident points based GPS

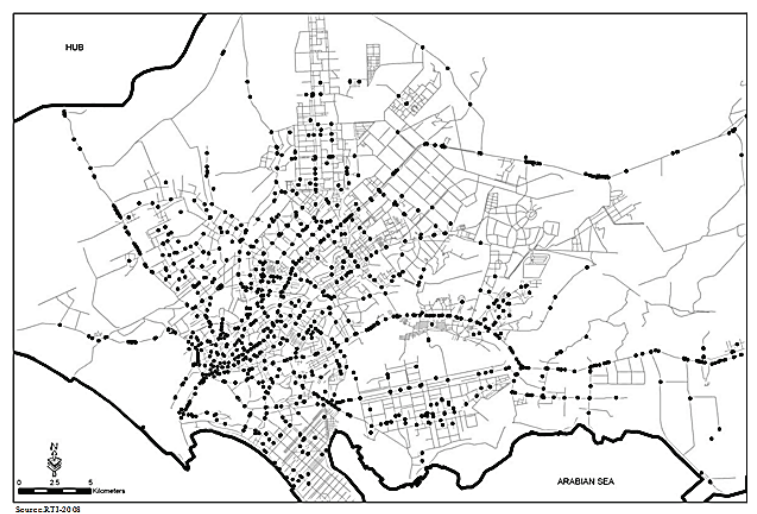

Figure 8 A generalized map of RTA locations, Karachi:2008

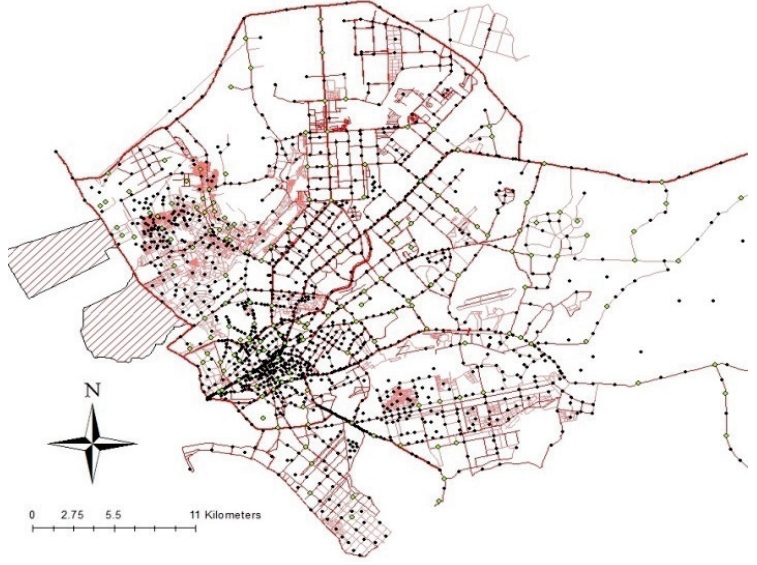

Figure 9 Variation in RTA' Pattern, respectively: Year 2011-12

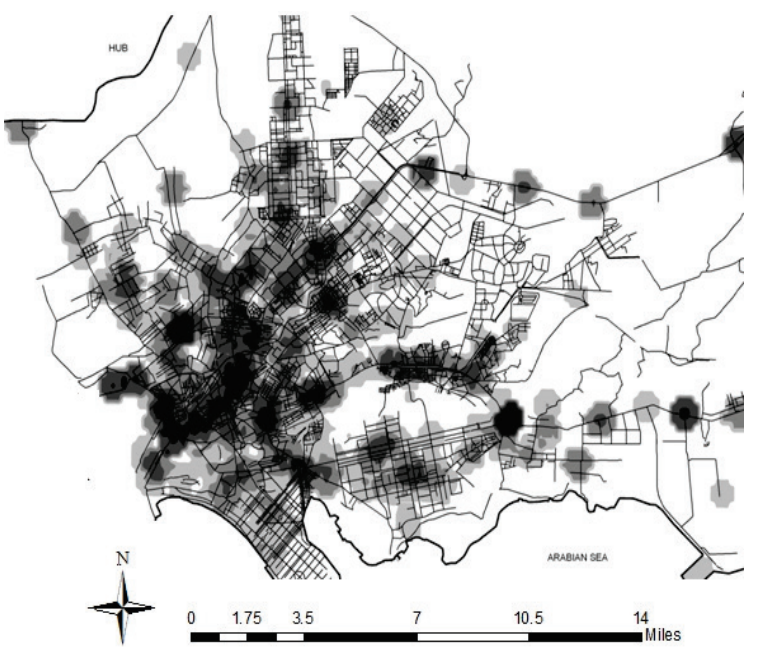

Figure 10 Change in RTA pattern of Karachi respectively year: from 2009- 2012

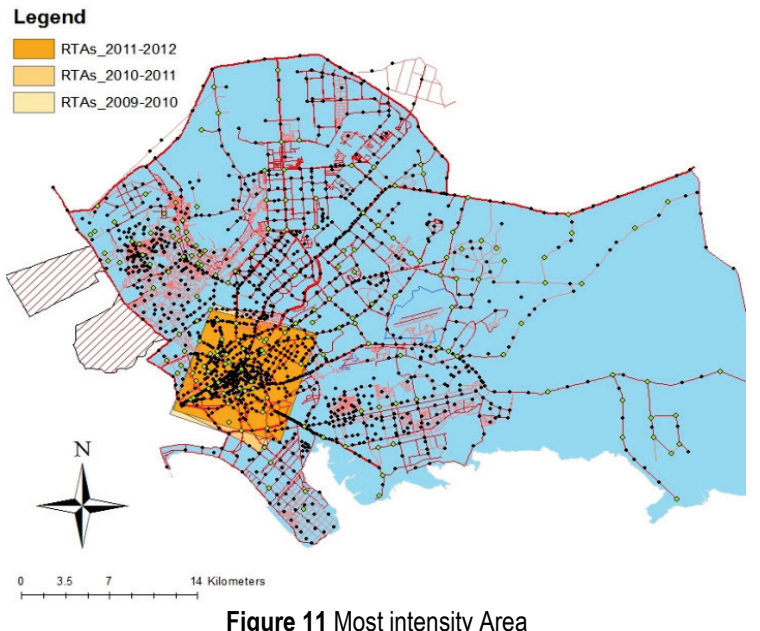

Shah Faisal Town faces minimum number of RTAs, including injuries (serious and minor) and fatalities cases. This town is smaller than others with minimum area of $11.76 \mathrm{~km}$. According to the 1998 census, the total population of this town is estimated 3, 35,823 inhabitants and reported 124 serious injuries cases, with five fatalities. This town is not significantly contributing in city development because this town is not connected with highway and commercial structure of the city well as, this town is away from the major five trauma centers which are located to some distance and accidents victims are not taken to anyone. 


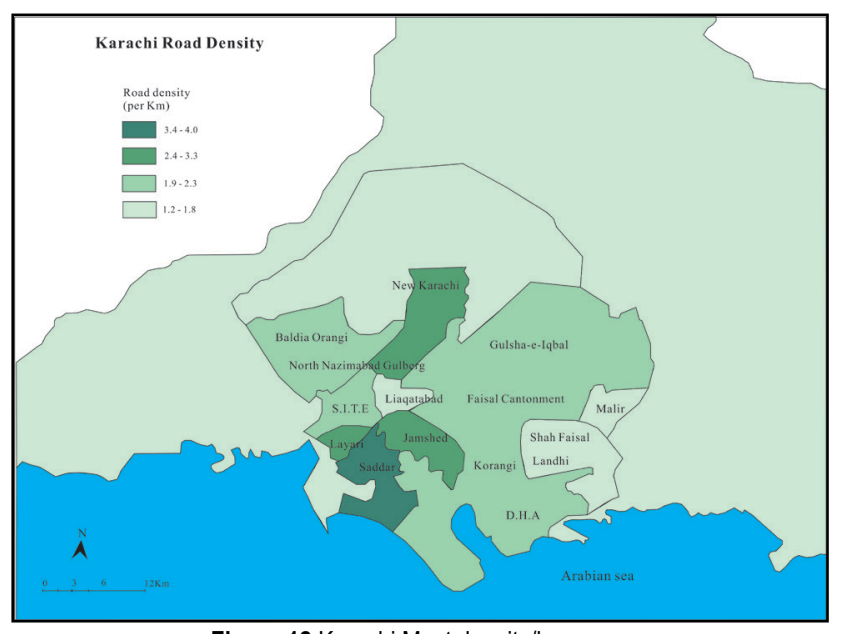

Figure 12 Karachi Most density/km area

However, maximum victims were reported from The Saddar Town. The total numbers of serious injuries cases were 3731 within area of $20.439 \mathrm{~km}$ and the total population of this area consists of $6,16,151$ people. This town is developed for multidisciplinary commercial activities and considered as center of the main city. Whereas Sadder town has major roads including Shahr-eFasial and M. A. Jinnah Road. Mostly in rush hours resulting the worst situation and facing maximum number of RTAs. The Korangi Town faced highest number of fatality victims in 2012 (see Figs. 13 and 14), while 394 victims were reported within area of $41.156 \mathrm{~km}$ and the total population of this area consists of 5, 46,504 (1998 census) people.

The Korangi Town has many important place for commercial activities, having many industries which one important industrial place known as K. I. T. E. (Korangi Industrial Trading Estate). This town consists of complex road networks resulting maximum number of RTAs, while vulnerable road user group especially in industrial area becomes a major cause of death [25-32].
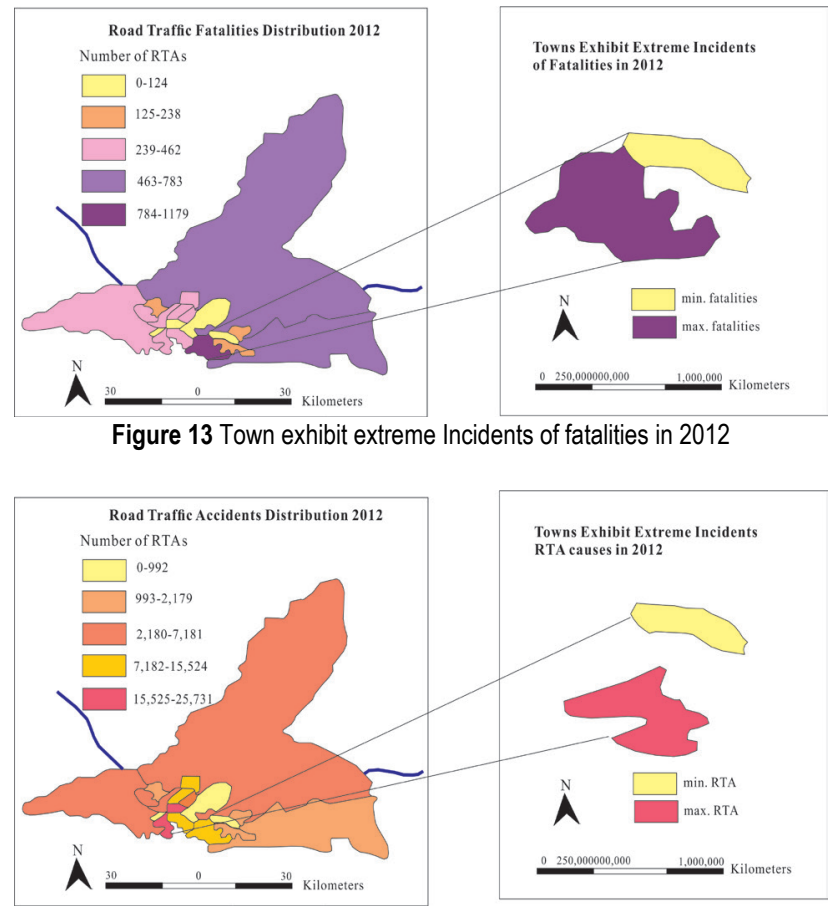

Figure 14 Towns exhibit extreme Incidents RTA causes in 2012
The victims' record (information) is confirmed from RTI surveillance program (Karachi). Here, data has been collected and manipulated accordingly, to the desired objectives to find out actual facts and figures. It has revealed, that the most of RTAs victims were young i.e. between 20-35 age group. It was also observed that most of accidents victims were bike riders/pillion. The gender wise division indicates that male's involvement is elevated than female's involvements in different RTAs. Main reason is that in our society male is always dominant and that's why mostly working people are men, whereas female choose to work at home as a house wife. Road safety becomes more significant for those victims that were depended one breadwinner. Consequently, road safety is related with relevant authority that strictly implementing the law for citizens on equity basis, in order to control or prevent unexpected loss of property or human life. Here, Emergency Medical Service (EMS) is a typical organization which usually assures community to safe in different emergency occurrences. Medically emergency service or ambulance medical service has been first introduced by Henry County in 1944, and county has divided district and made quick respond to incidental position within 24 hours. Whereas, every emergency location is different therefore requires more resources and handling by main station at various position. Without attention risk is difficult to control. It is estimated by Faster in 2004 that several No. of vehicles on roads intense highway environment required more resources to identify incident location or to deployment of ambulances that makes their work a difficult one.

\section{MODELS FOR EMS SYSTEM}

Probabilistic analytic models are dealing in significant amounts of research and usually in the hypercube queuing product. EMS is determined by special components from the strategic action plan; for instant, prepared planning, response, recovery and mitigation. EMS providers use a tool called "Compliance Table" for day by day operation [14]. This kind of table contains the pre computed set of ultimate locations to use available ambulances. If the quantity of accessible ambulances is adjustments, the ideal set of location might change. This modify occurs as a result of several events, such seeing that new call, a vehicle returning to service. Trauma attention center can makes best strategic motion plans about to approaching to zero death levels. There are many existing covering models regarding (probabilistic locations models for) EMS improvements but the most of the models follow the typical rules. The performance accuracy is expected and insurance coverage goes higher and higher with maximum number of zones. Church along with ReVelle (1974) designed a probabilistic model that explains the method of locating fixed variety of models. Based on the covering approach "a region is handled as covered if it is within the travel time associated with an ambulance. Also, it is vital that a vehicle should be around with a tremendous demand along with dispatch calls. Daskin and Stern in 1981, increased this thought with maximizing the number of zones included in a couple of ambulance, while covering (based) approach methods along with reliable plenty of EMS needed. Hence Stable area is efficient with respect to time and ambulance 
availability, using these models in base station is a requirement. Within urban area, the populace is dependent upon whether belong to individuals, business and commercial or residence area. The demand of particular services varies each occasionally. A decision support technique model can be developed to overcome this problem of ambulance area that evolves a model called TIMEXCLP, working on time variation in optimum predictable canceling site. Toregas in 1971 designed a set model it can reduce the price tag by investigating minimum number of ambulances/ vehicle faces of all the zones. There is no any regard of demands that each zone or an ambulance is busy or available for use in a covering model. Deterministic approaches are only determining the demand, travel time and service time for these models. Same as technological equipment that are used to act in response to the call so there is no any difference among the calls needing on life hold up of any extra services. Most busy vehicles did not get regard. That consequences in magnified probable values of system coverage and ReVelle improved this model EMS process best development will depend on model consent. Whereas, the simulation Models offers the whole structure on the system. Once a remedy arrives, the simulation model can be used to evaluate these solutions. City chosen model has become developed to cut back the vacation time along with percent of those calls not really be served with inside permissible time frame. The simulation models also facilitate in order to develop a choice support process for discovering crisis. While, TIMEXCLP protecting approach is useful as input pertaining to simulation when the requirements carry out by simulation then the locations can be used. If requirements are neglect to achieve, the particular TIMECLP can be re-run a new simulation in order to situate the particular locations. The iterative nature (these) models helped to discover the best (doable) results and the iteration proceeds until productivity meets the particular pre-determined need. No doubt, Simulation models are formally created to locate solutions by using the output and these models are enough to get an explicit [15-20].

\subsection{Modeling Issue}

Generally, system error can be found out through simulation modeling without experimentation in real system. It is useful to reduce actual cost and to avoid experimentation work which can be costly. Because the implementation is the execution of a plan, idea, model, design, specification, standard, algorithm, or policy in real system. And when it required to decision making then specific work that must completed before analysis can begin, included:

1) Must structure the granularity of model and zones;

2) Gathers demand, travel time, and service data based on that structure by Dai, Wang [21], and Yang.

\subsection{Zone Structure}

The particular zone structure is frequently molded based on the accessibility of the model and the data collection system. The most of urban or out of city EMS and FS systems have thousands of calls per year; it is really difficult to model down into the idle call level. As an alternative, here total calls in a "small area" are accumulated to a single zone. Mostly models are following the standard define rules, in which city is divided into small areas that called "zones" instead of locating the call location. At the first glance this expression is insignificant issue in modeling however expression can be deceived, as shown in Fig. 15. The system calculated nine calls and "1" (call) is each of the 9 address blocks, instead of utilizing separate locations. Herein, center of attention is perchance to aggregate all calls to the central block and representing on one zone $[22,23]$. The efficient accuracy is expected to become higher and higher in case of supplementary no of zones, by Hillsman and Rhoda in 1978 defined three basic errors that result from the creation zones [24].

a) Measurement of distance error for the call; it may happen if the original call location is not the incident place or fake call.

b) Measurement of distance error in case of true location is unknown.

c) Vehicle dispatching error in case of not to know the correct distance from EMS to aggregated zone.

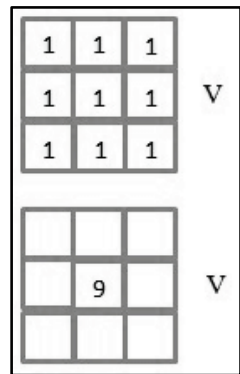

Figure 15 Call aggregations with a vehicle location

No doubt, the decisions regarding to vehicle dispatching and identifying location are critical factors in existing system success. Uncertainty "1" can't do both of these well. Therefore, both types of decisions have significant role, also must be made in a dynamic environment. The main objective of EMS or FS (fire station) deployment is to get the proper equipment to calls in a safe and timely fashion. But the problem of selecting the proper equipment is not in our focus. If calls responded in idle time period then there is no doubt that maximum no of request easily can entertained. No doubt, beside timeliness, there are other three main objectives needs to consider:

1. Reduce Cost

2. Reduce Coverage Equity

3. Reduce Labor Equity

\subsection{Maximum Coverage Location}

Maximum covering location problem sustains to provide maximum coverage for those demanded points that seeking maximum victims to be facilitated by ambulance service, and the mathematical formulation of this problem is stated as follows:

$$
\begin{gathered}
\text { Maximize } z=\sum_{i \in I} a_{i} y_{i} \\
\sum_{j \in N_{i}} x_{j} \geq y_{i} \text { all } i y \in I
\end{gathered}
$$


$\sum_{j \in J} x_{j}=P$

$x_{j}=(0,1)$ for all $j \in J$

$y_{i}=(0,1)$ for all $i \in I$

Where: $I$ - indicates the set of demanded points; $J$ indicates the set of incident facility; $S$ - the distance beyond which a demand point is considered/uncovered; ij $d$ - the shortest distance from node $i$ to node; $j x=\{1$ if a facility is allocated to site $j$, or 0 if not $\} ; i N=\{j J d S\} i j \in=$;

\section{EMPIRICAL MODELING FOR RESUE 15}

Author proposed [19], an optimization model dealing with EMS to assist the emergency service in the region of Karachi and estimated an empirical analysis of ambulance response times to a hospital and the time spent at the hospital, which the integrity and efficiency of the time threshold based on the acuity of the patient at the time when the 15 call is made. As it proved that, $t$ the convergence time for high priority call is reduced by assigning a low priority tag to the normal and fake calls. The model shows that the no. of ambulances varies from time to time over the course of the day. The model has association with the fire department so that model is suitable when analysing multi-region systems managed by a central planner, such as Region of Rescue 15.

\section{ROLL OF GIS EMS-ACTION OUTLINE}

Derekenaris, in 2001 affirmed that Cardiac arrest survival ratio is almost zero percent in case respond time is estimated more than eight minutes. Similarly, Kuehnert in 1999 confirms that Cardiac victims have highly survival rate, but in case of life support cardiopulmonary resuscitation (CRP) is provided within 4 minutes, after that survival chances is lessened. Derekenaris (2001) studied about the integration of GIS, GSM \& GPS technology in EMS in Greece by using well-organized data structure for implementation of graph indicating the demanded points on the road networks, and the shortest-path algorithm approved achieve the following: (1) By representation on the map positions of ambulances and trauma center locations, (2) To find the site of incident, (3) To select the appropriate ambulance for handling an emergency to incident, (4) To find route by implementation of shortest path algorithm, (5) The generation of victims' numbers, regarding to incidents. Casualties and demanding points calculated by various modes and presenting the team efforts, i.e. RTI (2008) Geo-database having detail information of all causalities within city (Karachi). By using command and features, then deputed ambulances by specialist, can improve following nearer zone and can better deal with existing modeling. Here, effective ambulance respond is vital to pick up serious and minor injuries victims, with an estimated $23 \%$ (see Tab. 3 ).

EMS's provider can use GIS to view or analyse the entire scene of the incident with the help of GPS or other sources of information. According to following present situation, to keep save human lives and suitable locations of EMS shelters have supreme significance to achieve an efficient result. There are different demands and circumstances at various locations and it can be classified by population/unit area, service demand, incident/rate, site feature, road and traffic condition, area of risk and loss of life, and etc. Effective emergency planning is necessary with ambulance pertinent locations, whereas, it is also required data collection by GPS for existing crash locations and major health cares or trauma centers, and RTAs correlate with GIS map that include layers of roads, streets and incidents locations. These layers included incident locations have been worked out. A Geospatial analysis done for converted spatial database geographical map shown (in Fig. 16). There are many Govt and private ambulance and service providers (include Rescue 15) and some private their included: Ehdi, Chippa and Aman, etc. In a quiet period the average time on scene is 15,75 minutes. EMS paramedics stay with their patients till get admission for care. The overload of work confers red alert and increased in costs of EMS are 0.20 minutes. Here, the study area is divided into four regions for EMS system (see Fig. 17) Time variable is estimated from two factors: Google map and driving directions obtained from the Rescue center [20].

Table 3 Emergency medical response by different agencies

\begin{tabular}{|c|c|c|c|c|}
\hline Mode & Fatal & $\%$ & Injury & $\%$ \\
\hline Ambulance & 390 & 59 & 3855 & 23 \\
\hline Others & 60 & 9 & 3855 & 23 \\
\hline Police & 25 & 4 & 180 & 1 \\
\hline Private & 121 & 18 & 11605 & 69 \\
\hline Public & 64 & 10 & 630 & 4 \\
\hline Total & 660 & 100 & 16872 & 100 \\
\hline
\end{tabular}
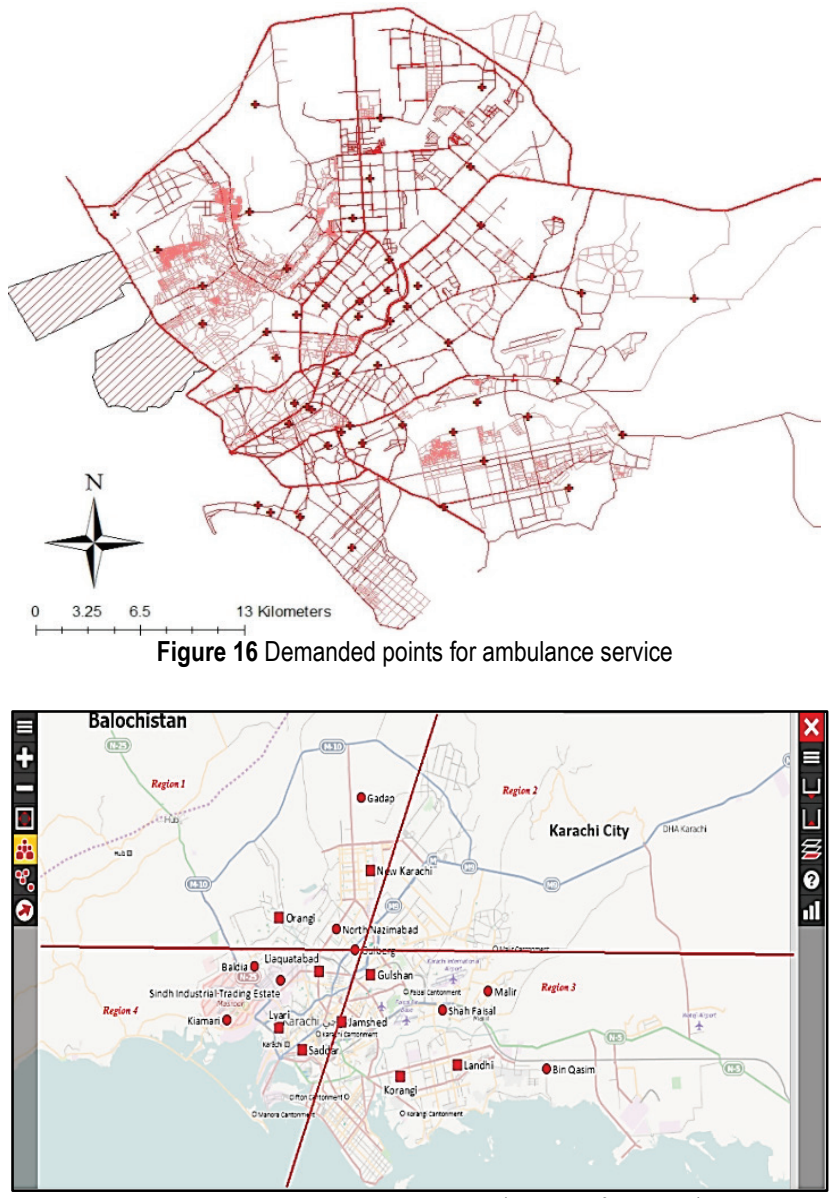

Figure 17 Karachi, Pakistan (Regions \& Rescue) 


\section{RESCUE LOCATIONS RESPONSE}

The disaster occurs within coverage area, the MERGe ambulances provide the service at glance at each region. A pictorial view (see Fig. 18) of ambulances participates in Rescue process MERGe group. The time consumption is calculated through the graph theory using the vertex as a valued route. Tab. 4 is a presenting a clear image of each service level and proposed coverage of the model during number of calls. The planning shows the overall call coverage up to $(86.30 \%$ etc.) in quiet period $84.20 \%$, in busy time $89 \%$. The average coverage time is $84.56 \%$. (see Fig. 18) and Tab. 4, Average time calculation of MERGe.

Table 4 Average time calculation of MERGe

\begin{tabular}{|c|c|c|c|c|}
\hline \multicolumn{5}{|c|}{ Table 4 Average time calculation of MERGe } \\
\hline Time & $\mathrm{T}(\mathrm{L})$ & Initial & Proposed & Overall \\
\hline Period & & Percent & Percent & Coverage-Percent \\
\hline Quiet & $10: 30$ & 28,93 & 22,30 & 94 \\
\hline Moderate & 12 & 37,50 & 31,90 & 93 \\
\hline Busy & 14 & 37,50 & 36,90 & 91 \\
\hline
\end{tabular}

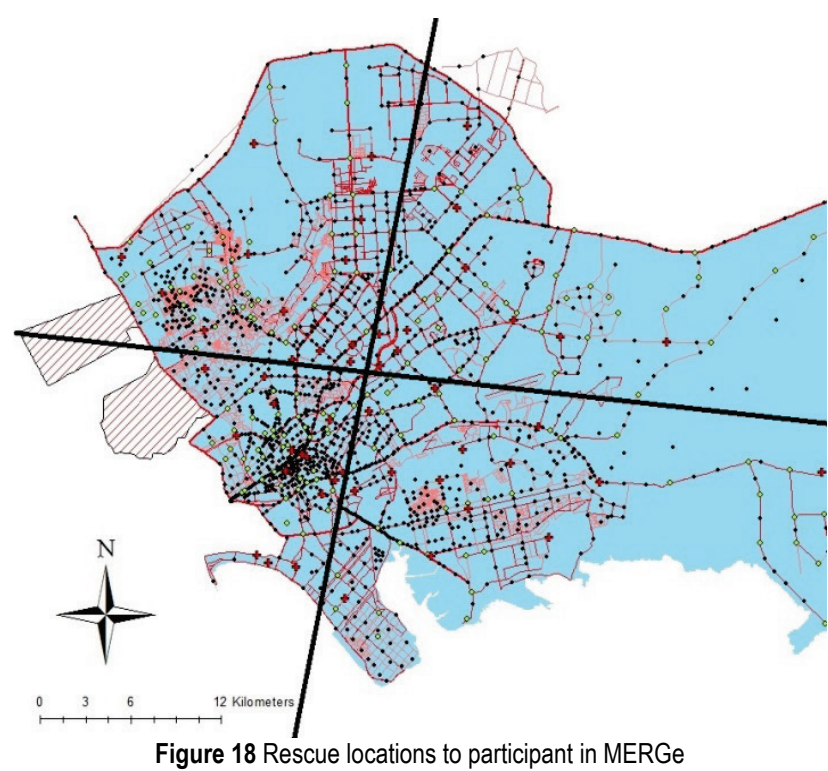

As outcome, Fig. 19 is presenting a coverage area of an ambulance within the white marsh manner. Whereas, the simulation results presenting the proposed modeling has a better converge time especially in busy period.

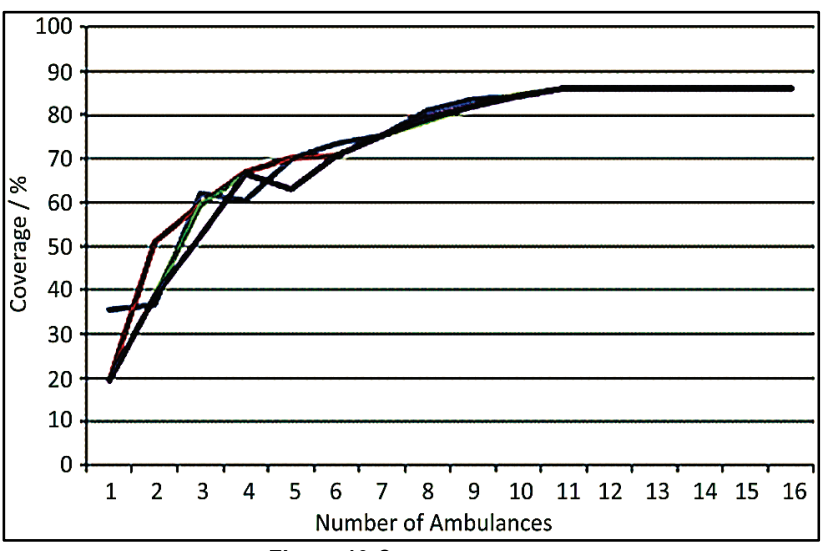

Figure 19 Coverage area response

\section{RECOMMENDATIONS}

An efficient accident database is a basic requirement for real time analysis but accident data alone is not sufficient. By integrate conventional arrangement with GIS, which recommends spatial referencing capabilities and geographical display, additional effective accident analysis system can be understood. Thus only way to deal with incident problem is by mapping and geographically display the position as accurately as possible. While diagnosis system is based on systematically [25] incident remedy process is often a continuous plan associated with performance, which turn is needed a concrete work on macro and micro levels. Mishaps often happened in extraordinary activities, so pertinent record and modeling is essential in emergency situation.

\section{DISCUSSION}

A vector map is vital to estimate variation of RTAs pattern. To assessment of Karachi district topographical map at sale of 1:250,000 were scanned, as the raster input. RTAs distribution is classified by recognizable and unrecognizable. Foremost, aim is to report the finding of RTA at Karachi and the primary data source is confirmed by (RTI) surveillance program: which received almost RTAs for during period Jan, 1, 2009 to Dec, 31, 2012. A total number of 99, 538 victims were enlisted. Annual incidence of RTI is calculated to be 184.3 per 100,000 populations and mortality is 5.7 per 100,000 populations. A significantly high AADT values inner city buffer or inside the city, which are 2.4 times the AADT value in the outskirts, and the total average AADT value almost 9.3 million is practically accurate. It is to be noted that maximum victims were reported in The Saddar Town during study time period. The total numbers of serious injuries cases were 3731 within area of $20.439 \mathrm{~km}$ and the total population of this area consists of 616,151 people. Sadder town has major roads including Shahr-e-Fasial and M.A Jinnah Road. Whereas, maximum fatalities were reported in Korangi Town, whereas 394 victims were reported in 2012 within area of $41.156 \mathrm{~km}$ and the total population of this area consists of 546, 504 people.

\section{CONCLUSION}

Author proposed an optimization model, to assist the emergency service in the region of Karachi, Here, GIS software is used to facilitate EMS's provider to view and analyse the entire scene of the accident with the help of GPS or other sources of information. Because model is associated with the fire department, thus, this model is pertinent when required analysing multi-region systems or managing, by a central planner such as Rescue 15 .

Further the author(s) are recommending some steps that needed to be in sequence get done:

Step\#1. Collection and compilation of casualties' record.

Step\#2. Computerization along with control in the accident records.

Step\#3. Identification along with prioritization of the accident black spot locations.

Step\#4. Hazards locations prioritization and diagnosis 
Step\#5. Make possible to enhance safety at least high casualty's locations by active EMS services, awareness programs and stick actions for vulnerable groups.

Step\#6. Comprehensive diagnosis along with countermeasures.

Step\#7. Define analysis/evaluation techniques

\section{REFERENCES}

[1] Basit, A., Riaz, M., \& Fawwad, A. (2015). Improving diabetes care in developing countries: the example of Pakistan. Diabetes research and clinical practice, 107(2), 224-232. https://doi.org/10.1016/j.diabres.2014.10.013

[2] Bhatti, J. A., Razzak, J. A., Lagarde, E., \& Salmi, L. R. (2010). Burden and factors associated with highway workzone crashes, on a section of the Karachi-Hala Road, Pakistan. Injury prevention, ip-2010. https://doi.org/10.1136/ip.2010.027532

[3] Ahmed, A. (2007). Road safety in Pakistan, Islamabad: National Road Safety Secretariat.

[4] Shamim, S., Razzak, J. A., Jooma, R., \& Khan, U. (2011). Initial results of Pakistan's first road traffic injury surveillance project. International journal of injury control and safety promotion, 18(3), 213-217. https://doi.org/10.1080/17457300.2011.555559

[5] Cathy, F. (2001). International Cooperation to Prevent Collision at Intersectionsll. http://www.tfhrc.gov/pubrds/ julaug01/preventcollisions.htm (12/17/2009)

[6] Shabbar, A. (2009). Personal communications with W. Uddin. University of Mississippi, June 2009.

[7] Afzal, A. (2009). Geospatial Analysis of Satellite Imagery for Mapping Road Inventory and Traffic Flow Attributes. M.S. Thesis, University of Mississippi, July 2009.

[8] Osborne, K. (2009). GIS-based Urban Transportation Infrastructure Management Using Spaceborne Remote Sensing Data. M.S. Thesis, University of Mississippi, December 2009.

[9] Road Traffic Injury research and Prevention Centre (2008). A journey from injury towards intervention Road causalities report 2008.

[10] Morgan, D., Eng, P., \& McGregor, R. V. (2003). Development of Intelligent Transportation Systems Strategic Plan for the Calgary Region. In The Transportation Factor 2003. Annual Conference and Exhibition of the Transportation Association of Canada. (Congres et Exposition Annuels de l'Association des transport du Canada).

[11] Rasjeed, J., Junaid, R., Muhammad, A., Mediha. (2010). GIS Based Placement and Route Planning of Emergency Response Vehicles (ERVs) for Efficient Incident Management, First International Conference on sustainable Transportation \& Traffic Management, Karachi Pakistan, IEDC-522-088.

[12] Channa, et al. (2008). Transport time to trauma facilities in Karachi: an exploratory study, http://www.ncbi.nlm.nih.gov/ pmc/articles/PMC2657275/

[13] Brice, J. H., Friend, K. D., \& Del Bridge, T. R. (2008). Accuracy of EMS-Recorded Patient Demographic Data. Pre hospital Emergency Care, 12(2), 187-191. https://doi.org/10.1080/10903120801907687

[14] Pozner, C. N., Zane, R., Nelson, S. J., \& Levine, M. (2004). International EMS systems: The United States: past, present, and future. Resuscitation, 60(3), 239-244. https://doi.org/10.1016/j.resuscitation.2003.11.004

[15] ReVelle, C. S., \& Eiselt, H. A. (2005). Location analysis: A synthesis and survey. European Journal of Operational Research, 165(1), 1-19. https://doi.org/10.1016/j.ejor.2003.11.032
[16] Brotcorne, L., Laporte, G., \& Semet, F. (2003). Ambulance location and relocation models. European journal of operational research, 147(3), 451-463. https://doi.org/10.1016/S0377-2217(02)00364-8

[17] Erkut, E. et al. (2001). Improving the emergency service delivery in St. Albert. Info, 39(4), 416-433. https://doi.org/10.1080/03155986.2001.11732451

[18] Erkut, E., Ingolfsson, A., \& Budge, S. (2008). Maximum availability/reliability models for selecting ambulance station and vehicle locations: a critique. Natural Sciences and Engineering Research Council of Canada (NSERC), 111.

[19] Asim Azim, M., Jianwu, D., Yangping, W., \& Fengwen, Z. (2014). Coverage based empirical modelling for EMS rescue system of Karachi (Pakistan). Tehnički vjesnik, 21(3), 561566.

[20] Gendreau, M., Laporte, G., \& Semet, F. (2005). The maximal expected coverage relocation problem for emergency vehicles. J Oper Res Soc., 57(1), 22-28. https://doi.org/10.1057/palgrave.jors.2601991

[21] Power, D. J., Sharda, R., \& Burstein, F. (2015). Decision support systems. John Wiley \& Sons, Ltd. https://doi.org/10.1002/9781118785317.weom070211

[22] Brotcorne, L., Laporte, G., \& Semet, F. (2003). Ambulance location and relocation models. European journal of operational research, 147(3), 451-463. https://doi.org/10.1016/S0377-2217(02)00364-8

[23] Gendreau, M., Laporte, G., \& Semet, F. (2001). A dynamic model and parallel tabu search heuristic for real-time ambulance relocation. Parallel computing, 27(12), 16411653. https://doi.org/10.1016/S0167-8191(01)00103-X

[24] Hillsman, E. \& Rhoda, R. (1978). Errors in measuring distances from population to service centers. Annals of Regional Science, 12, 74-88. https://doi.org/10.1007/BF01286124

[25] Government of Sindh. A Transport Policy, Sindh Transport Department 2011.

[26] Jooma, R., Shabbr, M., Jehangir, A., Hussain, S. A., \& Razzak, J. (2010). Road Casualty Report 2009 by (RTIPC) Road Traffic Injury and Prevention Center 2009.

[27] Jooma R, Shabbr M, Jehangir A, Hussain SA, Razzak J. Road Casualty Report 2010 by (RTIPC) Road Traffic Injury and Prevention Center 2010.

[28] Jooma, R., Shabbr, M., Jehangir, A., Hussain, S. A., \& Razzak, J. (2011). Road Casualty Report 2011 by (RTIPC) Road Traffic Injury and Prevention Center, Karachi 2011.

[29] Government of Pakistan, District Report of Karachi, Population and Housing Census 1998, Population Census Organization, Islamabad, Pakistan 1998.

[30] Shahbir, Z. \& Kazmi, S. J. H. (2013). Spatial Framework for the Assessment of Road Traffic Accidents in Karachi. Journal of Applied Science, 9, 525-532.

[31] Razzak, J. A., Bhatti, J. A., Ali, M., Khan, U. R., \& Jooma, R. (2011). Average out-of-pocket healthcare and work-loss costs of traffic injuries in Karachi, Pakistan. Int $J$ Injury Control Safety Promot, 18(3), 199-204 https://doi.org/10.1080/17457300.2011.551942

[32] Jooma, R., Razzak, J., Ahmed, M., \& Madiha. (2010). GIS based Placement and Route Planning of Emergency Response Vehicle (ERVs) for Efficient Incident Management. 


\section{Contact information:}

\section{Muhammad ASIM AZIM}

(Corresponding author)

$12^{\text {th }}$ Floor Unit 8, Amarin Tower,

496-502 Ploenchit Road, Lumpini, Pathumwan, Bangkok 10330, Thailand

E-mail: gis.edu_zjtu@yahoo.com

\section{Dang JIANWU}

School of Electronics and Information Engineering,

Lanzhou Jiaotong University,

88 West Anning Road Lanzhou, Gansu Province, P. R. China 730030

E-mail: dangjw@mail.|zjtu.cn

\section{Wang YANGPING}

802 Post Box Lanzhou Jiaotong University,

88 West Anning Road Lanzhou, Gansu Province, P. R. China 730070

E-mail: wangyangping@mail.Izjtu.cn

\section{Tarique AZIZ}

College of Electrical Engineering, Yuquan Campus, Zhejiang University,

38 Zheda Road, Hangzhou, P. R. China, 310027

E-mail: tariq.aziz@zju.edu.cn

\section{Zhai FENGWEN}

802 Post Box Lanzhou Jiaotong University,

88 West Anning Road Lanzhou Gansu Province, P. R. China 730070

E-mail: 930843420@qq.com 